\title{
CONCEPÇÃO DE DOCÊNCIA: O QUE PENSAM OS PROFESSORES ALFABETIZADORES DA REDE MUNICIPAL DE ENSINO DE CAMPO GRANDE- MS?
}

\author{
Vilma Miranda de Brito ${ }^{1}$, Rosangela Cristina Teixeira Fernandes ${ }^{2}$ \\ ${ }^{1}$ Doutora em Educação pela Universidade Federal de Mato Grosso do Sul - UFMS, Campo Grande, Mato Grosso do Sul. \\ Atualmente é professora Sênior da Universidade Estadual de Mato Grosso do Sul - UEMS, Mato Grosso do Sul. ORCID iD: \\ https://orcid.org/0000-0002-1573-5339 E-mail: vilmiranda2015@gmail.com \\ ${ }^{2}$ Pedagoga formada pela Universidade Federal do Rio Grande do Norte. Pós-Graduada em Gestão da sala de aula nos anos \\ iniciais do Ensino Fundamental e suas metodologias pelo Instituto de Ensino Superior da Funlec - IESF. Mestre em \\ Educação pela Universidade Estadual de Mato Grosso do Sul - UEMS. ORCID iD: https://orcid.org/0000-0003-4732-6844 E- \\ mail: rosangelactf@hotmail.com
}

\section{RESUMO}

Esse artigo apresenta os resultados da pesquisa realizada no ano de 2018, com o objetivo investigar a concepção de docência dos professores alfabetizadores a partir das políticas de formação continuada desenvolvidas na Rede Municipal de Ensino (REME) de Campo Grande/MS. Nessa perspectiva, adotou-se a pesquisa qualitativa para abordar e discutir as políticas públicas de formação de professores alfabetizadores, perpassando pelas legislações e programas de âmbito federal (Pró-Letramento e PNAIC) e municipal (Aposta no professor). A coleta de dados ocorreu por meio de entrevistas semiestruturadas com professores alfabetizadores nas escolas municipais de Campo Grande/MS. A pesquisa evidenciou que a concepção de docência do professor alfabetizador que atua na REME ora compreende a alfabetização como um processo gradual de aprendizagem, ora compreende a aprendizagem da alfabetização articulada com a maturidade. Identificamos, também, a concepção de docência permeada pela afetividade e pela aptidão, traçando, assim, um perfil de professor alfabetizador. E, por fim, a concepção de docência embasada na necessidade de dominar saberes sistematizados que permeiam o processo alfabetizador, o que nos possibilitou refletir e discutir sobre as formações continuadas ofertadas aos docentes da REME que centralizam as discussões nas práticas de ensino para alavancar índices educacionais. Concluiu-se que é urgente a reestruturação das formações de modo a viabilizar discussões que aliem teoria, prática e especificidades vivenciadas na sala de aula, possibilitando a aquisição de novos saberes e um olhar crítico sobre o processo de ensino-aprendizagem, proporcionando estudos e reflexões que se articulem e ressignifiquem a concepção de docência do professor alfabetizador.

Palavras-chave: Formação de professores alfabetizadores. Concepção de docência. Formação continuada.

\section{CONCEPTION OF TEACHING: WHAT DO LITERACY TEACHERS OF THE MUNICIPAL SCHOOL NETWORK OF CAMPO GRANDE- MS?}

\section{ABSTRACT}

This article showed the results of the research conducted in 2018, with the objective of investigating the teaching conception of literacy teachers from the policies continuing education developed in the Municipal Education Network (REME) of Campo Grande/MS. In this perspective qualitative research was adopted to address and discuss public policies for the training of literacy teachers, going through the laws and programs of federal (PróLetramento and PNAIC) and municipal (Bet on the teacher). Data collection occurred through semi-structured interviews with literacy teachers in municipal schools in Campo Grande/MS. The research showed that the teaching conception of the literacy teacher who works at REME now understands literacy a gradual learning process, now comprises the learning of literacy articulated with maturity. We also 
identified the concept of teaching permeated by affection and aptitude, thus tracing a literacy teacher profile. And finally, the conception of teaching based on the need to master systematized knowledge that permeates the literacy process, which allowed us to reflect and discuss the continuing formations offered to REME professors who centralize discussions in teaching practices to leverage educational indices. It was concluded that there is an urgent need to restructure formations in order to enable discussions that include theory, practice and specificities experienced in the classroom enabling the acquisition of new knowledge and a critical look at the teaching-learning process, providing studies and reflections that articulate and resign the teaching conception of the literacy teacher.

Keywords: Training of literacy teachers. Concept of teaching. Continuing training.

\section{CONCEPCIÓN DOCENTE: QUÉ PIENSAN LOS PROFESORES DE ALFABETIZACIÓN EN LA RED MUNICIPAL DE EDUCACIÓN EN CAMPO GRANDE - MS?}

\section{RESUMEN}

Este artículo presenta los resultados de la investigación realizada en 2018, con el objetivo de investigar la concepción de los profesores estudiantes de alfabetización de las políticas de educación continua desarrolladas en la Red Municipal de Educación (REME) de Campo Grande/MS. Desde esta perspectiva, se adoptó una investigación cualitativa para abordar y discutir políticas públicas para la formación de los profesores de alfabetización, a través de la legislación y programas de federal (Pro-Literacy y PNAIC) y municipal (Bet en el maestro). La recopilación de datos se produjo a través de entrevistas semiestructuradas con profesores de alfabetización en las escuelas municipales de Campo Grande/MS. La investigación mostró que la concepción docente del profesor de alfabetización que trabaja en REME ahora entiende la alfabetización como un proceso de aprendizaje gradual, ahora comprende el aprendizaje de la alfabetización articulada con madurez. También identificamos la concepción de la enseñanza impregnada de afecto y aptitud, tramando así un perfil de profesor de alfabetización. Y por último, la concepción de la enseñanza basada en la necesidad de dominar el conocimiento sistematizado que impregna el proceso de alfabetización, que nos permitió reflexionar y discutir la formación continua ofrecida a los maestros de REME que centralizan los debates en las prácticas docentes para aprovechar los índices educativos. Se llegó a la conclusión de que es urgente reestructurar las formaciones con el fin de permitir discusiones que incluyan teoría, práctica y especificidades experimentadas en el aula, permitiendo la adquisición de nuevos conocimientos y una mirada crítica al proceso de enseñanza-aprendizaje, proporcionando estudios y reflexiones que articulan y resignan la concepción docente del profesor de alfabetización.

Palabras clave: Formación de alfabetizadores. Concepción de la docencia. Entrenamiento en curso.

\section{INTRODUÇÃO}

O presente artigo evidencia o resultado de uma pesquisa realizada no decorrer do ano de 2018, que culminou na dissertação de Mestrado Profissional em Educação pela Universidade Estadual de Mato Grosso do Sul - UEMS. O objetivo geral da pesquisa foi investigar a concepção de docência dos professores alfabetizadores a partir das políticas de formação continuada desenvolvidas na REME de Campo Grande/MS desde $o$ ano de 2005.

A concepção de docência é constituída por saberes e experiências vivenciadas pelo professor ao longo de todo o seu processo formativo. Se constitui em fontes de "[...] convicções, crenças ou representações, [...], em relação ao [...] papel do professor, aprendizagem, características dos alunos, estratégias pedagógicas, gestão da classe etc.". (TARDIF; RAYMOND, 2000, p. 220). A concepção de docência determina, portanto, o modo como o professor compreende e encaminha o processo de alfabetização no contexto escolar.

$A$ rotatividade de docentes efetivos e não efetivos, destacada no Plano Municipal de Educação de Campo Grande-MS (PME 2015-2025) como um dos obstáculos e pontos fracos, associada 
à obstáculos e oportunidades para a atuação, formação, valorização e carreira dos profissionais da educação, foi um dos motivos para a escolha do tema de pesquisa. Além disso, a consequente rotatividade docente em turmas de alfabetização, que é mais preocupante ainda em virtude do investimento em formação continuada que os governos fizerem nos últimos anos com a implementação de Programas para o ciclo de alfabetização, foi decisiva para a delimitação do objeto de investigação e acabou impulsionando a investigação da temática.

Esta constatação norteou o percurso da pesquisa, tanto a bibliográfica quanto a empírica. A pesquisa empírica foi realizada por meio de entrevistas com professores alfabetizadores do 1 , 2ㅇ e 3 o anos do Ensino Fundamental, lotados em escolas municipais da cidade de Campo Grande/MS.

Os resultados foram analisados e discutidos à luz de autores como Tardif e Raymond (2000), Bolzan e Millani (2013), Valle (2014), Hoça (2015), entre outros, cujas discussões se relacionam à concepção de docência do professor alfabetizador.

$\mathrm{Na}$ oportunidade também tratamos das políticas públicas de formação inicial e continuada, abordando as diretrizes do curso de Pedagogia, a Lei de Diretrizes e Bases da Educação - LDB (Lei 9394/96) e os programas de formação ofertados pelo Ministério da Educação (MEC) em parceria com os entes federados, centralizando as discussões no Pró-Letramento, Pacto Nacional pela Alfabetização na Idade Certa (PNAIC) e Aposta no Professor.

Iniciamos, portanto, fazendo o delineamento da pesquisa expondo os caminhos percorridos no decorrer do desenvolvimento da investigação. Em seguida, discorremos sobre as concepções de docência embutidas nas formações de professores alfabetizadores, tratando sobre a formação realizada no curso normal, no magistério, no curso de Pedagogia e, também, nas formações continuadas ofertadas por meio dos programas Pró-Letramento (2005), PNAIC (2013) e Aposta no Professor (2005) no município de Campo Grande/MS. Por fim, expomos e analisamos os dados coletados discorrendo sobre a concepção de docência que norteia o processo alfabetizador sob a ótica dos professores alfabetizadores, analisando e encaminhando as discussões para as considerações finais.

\section{DELINEAMENTO DA PESQUISA}

Durante 0 processo formativo os professores alfabetizadores convivem com pessoas e vivenciam situações que podem determinar a sua atuação profissional, tendo em vista "[...] o impacto que toda essa experiência [...] tem na construção de modelos e concepções do que seja 'o professor', 'a aula', ou do que seja 'ensinar'. " (DINIZ-PEREIRA, 2007, p. 86). Essa experiência é adquirida quando em situações de interação e mediação sistemáticas, dentro e fora do contexto escolar, uma vez que

[...] os saberes adquiridos durante a trajetória préprofissional, isto é, quando da socialização primária e sobretudo quando da socialização escolar, têm um peso importante na compreensão da natureza dos saberes, do saber-fazer e do saber-ser que serão mobilizados e utilizados em seguida quando da socialização profissional e no próprio exercício do magistério. (TARDIF, 2002, p. 69).

Evidenciamos, também, que as formações têm grande influência na constituição da concepção de docência alfabetizadora. É durante a formação inicial no curso de Pedagogia que o professor adquire os saberes sistematizados relacionados à alfabetização e letramento.

Por não existir concurso específico para professor alfabetizador, só são considerados alfabetizadores os pedagogos, efetivos ou convocados, que assumem as turmas do 1으, 2으 e 3응 anos do Ensino Fundamental. Tal fato contribui para a rotatividade docente à medida que não há uma obrigatoriedade de permanência nessa função, ocasionando a lotação de docentes com e sem aptidão para trabalhar nessa etapa escolar.

Logo, são ofertadas as formações continuadas por meio de programas como PróLetramento, PNAIC e Aposta no Professor, com o objetivo de construir "[...] uma professoralidade, [..] um perfil/performance profissional [...]", 
concentrando as discussões na prática docente, no encaminhamento do processo de ensinoaprendizagem, visando efetivar 0 processo alfabetizador até o final do 30 ano do Ensino Fundamental. (MOROSINI et al., 2006, p. 354).

Diante dessa constatação emergiram alguns questionamentos que impulsionaram o desenvolvimento desta pesquisa: Qual a concepção de docência do profissional que tem a incumbência de alfabetizar? Existe alguma especificidade para ser professor alfabetizador? Quais as políticas públicas municipais específicas para a formação do professor alfabetizador?

Trata-se de uma pesquisa de abordagem qualitativa tendo em vista que "[...] trabalha com o universo de significados, motivos, aspirações, crenças, valores e atitudes, [...]", buscando compreender o objeto de estudo em sua essência, isto é a concepção de docência do professor alfabetizador. (MINAYO et al., 2002, p. 21-22).

Para subsidiar teoricamente a investigação e contextualizar as informações sobre a formação de professores alfabetizadores, realizamos uma pesquisa bibliográfica e documental reunindo informações "[...] sobre leis [...] de educação, processos e condições escolares, planos de estudo, requisitos de ingresso, [...]", que garantissem a análise consistente do objeto pesquisado. (TRIVIÑOS, 1987, p. 111).

Realizamos a pesquisa de campo em 5 (cinco) escolas, cada uma localizada em uma região urbana da cidade de Campo Grande/MS, selecionadas com base no Índice de Desenvolvimento da educação Básica (IDEB), ano de 2015, dados utilizados apenas como forma de delimitar um campo de investigação para coleta de dados. Portanto, foram selecionadas 1 (uma) escola da região do Imbirussu, 1 (uma) da região do Segredo, 1 (uma) da região do Prosa, 1 (uma) da região da Bandeira e 1 (uma) da região do Anhanduizinho. Em cada uma das instituições selecionamos 1 (um) docente alfabetizador indicado pela gestão escolar para ser entrevistado, totalizando 5 (cinco) sujeitos da pesquisa. Dentre os sujeitos selecionados, 2 (dois) eram lotados no 1 을 ano, 2 (dois) no 2o ano e 1 (um) no 3 음 ano do Ensino Fundamental.

A coleta de dados aconteceu na própria instituição escolar, em dia e horário determinados pela gestão, conforme planejamento do professor, por meio de entrevista semiestruturada, que é um instrumento que "[...] parte de certos questionamentos básicos, apoiados em teorias e hipóteses, [...], e [...], oferecem amplo campo de interrogativas, fruto de novas hipóteses que vão surgindo [...]", possibilitando, assim, maior interação entre o pesquisador e o sujeito pesquisado. (TRIVIÑOS, 1987, p. 146).

As entrevistas foram gravadas e transcritas, sendo que o material empírico gerado foi examinado pela análise de conteúdos mediante categorização e interpretado à luz de estudos bibliográficos.

\section{AS CONCEPÇÕES DE DOCÊNCIA EMBUTIDAS NAS FORMAÇÕES DE PROFESSORES ALFABETIZADORES}

$O$ primeiro passo rumo à formação de professores no Brasil foi dado a partir da independência do Brasil, com o aparecimento das Escolas Normais. Entretanto, foi com a proclamação da República que essas instituições se consolidaram e se constituíram como lócus de formação docente, centralizando os estudos formativos no método analítico de alfabetização.

A implantação dos Institutos de Educação nos estados do Rio de Janeiro e São Paulo, a partir de 1932, foi o primeiro passo rumo à formação universitária no Brasil. Posteriormente, foram substituídos pela Faculdade Nacional de Filosofia da Universidade do Brasil, cujo ensino seguia a fórmula 3+1 com separação entre o bacharelado e a licenciatura.

A concepção de docência que norteava esses processos formativos via o professor "[...], como um técnico, um especialista que aplica com rigor, na sua prática cotidiana, as regras que derivam do conhecimento científico e do conhecimento pedagógico". (DINIZ-PEREIRA, 1999, p. 111 e 112). Assim, focalizavam na ação pedagógica, nas habilidades práticas da sala de aula.

Só em 1961 a formação do professor primário para atuar de 1 a a 4 a série passou a ser oferecida através do Curso Normal. No entanto, dez anos depois o Curso Normal deu lugar à Habilitação Específica do Magistério (HEM), curso profissionalizante com foco na instrumentalização técnica, onde a concepção de docência relacionavase ao "[...] papel [...] de passiva conformidade com as recomendações práticas dos teóricos e 
pesquisadores educacionais", centralizando as discussões na estruturação do currículo (objetivos, avaliação, conteúdo, etc.) para garantir resultados. (DINIZ-PEREIRA, 2014, p. 35).

Em meio à mobilização social impulsionada pelo fim do Regime Militar, o processo educativo passou a ser visualizado como meio de transformação social, sendo os professores os principais agentes desse processo. Logo, “[...] a prática dos professores deixa de ser considerada neutra e passa a constituir-se em uma prática educativa transformadora" (DINIZ-PEREIRA, 2013, p. 147). Nessa mesma época, o curso de Pedagogia que era até então voltado à formação de especialistas, vai sendo reestruturado para a licenciatura com o intuito de formar professores para atuarem na educação infantil e séries iniciais do 1 음a.

A partir dos anos 1990, com a globalização e avanços tecnológicos, o processo educativo reestrutura-se visando formar sujeitos capacitados para atender as necessidades da sociedade capitalista, exigindo, portanto, professores preparados para atuar nesse novo cenário educacional.

Nessa perspectiva, sustentados pelos ideários de instituições como Organização das Nações Unidas para a Educação, a Ciência e a Cultura (UNESCO) e o Banco Mundial, reformulamse os programas de formação continuada visando "[...] a capacitação profissional e o aproveitamento da produção científico-tecnológica [...]", ficando a concepção de docência limitada à reprodução de métodos oficiais de ensino. (FRIGOTTO; CIAVATTA, 2003, p. 99).

Desde então, esse é o tipo de formação oferecida pelos entes federados aos profissionais de ensino visando $o$ aumento de índices educacionais aferidos por meio de avaliações nacionais aplicadas aos alunos da educação básica, embutindo, assim, uma política de responsabilização que tende a culpabilizar os docentes pelos baixos índices aferidos.

Em meio às mudanças no cenário educacional brasileiro, foi aprovada a LDB n. 9.394, de 20 de dezembro de 1996. Esse documento basilar da educação nacional foi alvo de inúmeros debates promovidos por educadores, principalmente com relação ao curso de Pedagogia, já que a lei enfatizava seu oferecimento em nível de bacharelado, chocando-se com o processo formativo até então desenvolvido no interior das instituições de ensino superior, que era voltado para a licenciatura.

Os debates geraram pareceres que impulsionaram a aprovação das Diretrizes Curriculares Nacionais para o Curso de Graduação em Pedagogia, Licenciatura, pelo Conselho Nacional de Educação (CNE) em 15 de maio de 2006, documento que estabeleceu o curso em nível de licenciatura voltando a formação docente para atuação na Educação Infantil, séries iniciais do Ensino Fundamental e Ensino Médio (normal e profissional na área de serviços e apoio escolar). Logo, a concepção de docência supõe um modo particular de apreensão, configurando-se como conceito alargado, que vai além da relação ensinoaprendizagem, [...]" ultrapassando, portanto, os limites da sala de aula e ampliando o espaço de atuação do pedagogo. (VIEIRA, 2011, p. 131).

Por abranger a formação de professores para atuação nas séries iniciais do Ensino Fundamental, o curso de Pedagogia assumiu a incumbência de formar alfabetizadores. E é nessa habilitação que os futuros docentes estudam os conceitos sistematizados que norteiam a concepção de alfabetização e o processo alfabetizador.

Até o início da década de 1980 a concepção de alfabetização que norteava o processo de ensino-aprendizagem no Brasil centrava-se na aprendizagem do sistema convencional da escrita, isto é, na aprendizagem do sistema alfabético e ortográfico da escrita. Para tanto, os professores alfabetizadores utilizavam métodos diversificados sintéticos (fônico, silábico) e analíticos (palavração, sentenciação, método global) - para a consecução desse objetivo. Tais métodos vinham materializados nas cartilhas juntamente com o manual destinado ao professor alfabetizador detalhando como o processo de ensinoaprendizagem deveria ser encaminhado. Logo, "Havia um método, mas não uma teoria" (SOARES, 2003 , p. 17). Nesse contexto, o professor encaminhava o processo de ensino-aprendizagem seguindo as orientações propostas nas cartilhas e manuais para fazer a criança ler e escrever para depois, com essas habilidades já consolidadas, desenvolvê-las em práticas de leitura e produção de texto. 
No ano de 1980, as pesquisas de Emília Ferreiro e Ana Teberosky sobre a psicogênese da língua escrita, mesmo sem essa intencionalidade, acabaram estabelecendo parâmetros de ensino que passaram a nortear as ações dos professores alfabetizadores no Brasil. Assim, associado ao construtivismo, de Jean Piaget, os estudos relacionados à psicogênese da língua escrita foram incorporados pelos educadores brasileiros e adentraram as instituições de ensino, influenciando, significativamente, o trabalho dos professores alfabetizadores nas salas de aula. Esses estudos adentraram os cursos de Pedagogia ressignificando a formação e o trabalho dos professores alfabetizadores nas salas de aula, uma vez que:

\section{[...] deslocando o eixo das discussões dos métodos de ensino para o processo de aprendizagem da criança (sujeito cognoscente), o construtivismo se apresenta, não como um método novo, mas como uma 'revolução conceitual', demandando, dentre outros aspectos, abandonarem-se as teorias e práticas tradicionais, desmetodizar-se o processo de alfabetização e se questionar a necessidade das cartilhas. (MORTATTI, 2006, p. 10).}

Voltava-se o olhar, portanto, para o modo como as crianças aprendiam e ler e escrever, acreditando-se que elas se alfabetizavam apenas interagindo com a escrita, cabendo ao professor mediar e encaminhar ações para efetivar a aprendizagem dos alunos. A concepção de alfabetização ${ }^{1}$ que passou a nortear o processo de

\footnotetext{
${ }^{1} A$ alfabetização é um termo/conceito que é "[...] utilizado contemporaneamente, no Brasil, para designar processo de ensino e aprendizagem que [...] comportou diferentes sentidos e foi designado por diferentes termos, correspondentes a diferentes conceitos, tais como: 'ensino das primeiras letras'; 'ensino de leitura'; 'ensino simultâneo de leitura e escrita'. A utilização do termo 'alfabetização' consolidou-se, no Brasil, a partir do início do século XX, sempre relacionado predominantemente com processos de escolarização; e, a partir das décadas finais desse século, passou a ser utilizado tanto em sentido amplo ('alfabetização matemática', 'alfabetização digital', dentre outros) quanto em sentido mais restrito e específico: 'ensino aprendizagem inicial de leitura e escrita". (MORTATTI, 2011, p. 8).
}

ensino aprendizagem centrava-se no ideário de que a criança aprendia a ler e escrever apenas interagindo com a escrita. Assim, por meio dessa interação, ela ia "[...] construindo hipóteses a respeito da escrita, e, com isso, [...] aprendendo a ler e a escrever numa descoberta progressiva". (SOARES, 2003, p. 17).

Nesse sentido, a alfabetização sob a perspectiva do letramento - alfabetizar-letrando significa ensinar o sistema convencional da escrita aliado às habilidades de uso da leitura e escrita em práticas sociais (SOARES, 2003). Portanto, a alfabetização (aquisição do sistema convencional da escrita) e o letramento (uso das habilidades de ler e escrever em práticas sociais) apesar de se constituírem distintos quanto ao objeto de conhecimento e ensino-aprendizagem, são processos indissociáveis, tendo em vista que:

[...] a alfabetização só tem
sentidor quando
desenvolvida no contexto de
práticas sociais de leitura e
de escrita e por meio dessas
práticas, ou seja, em um
contexto de letramento e
por meio de atividades de
letramento; este, por sua
vez, só pode desenvolver-se
na dependência da e por
meio da aprendizagem do
sistema de escrita. (SOARES,
2004, p. 97).

Com o advento do letramento, a leitura e a escrita como prática social tomaram visibilidade, reconfigurando a definição de ser alfabetizado que já não englobava apenas o domínio do sistema alfabético e ortográfico da língua, mas também o uso dessas habilidades em práticas sociais, ou seja, alfabetizar letrando ou alfabetizar na perspectiva do letramento. Assim a alfabetização requer a mediação de professores preparados para atenderem as peculiaridades dessa etapa escolar para garantir a inserção das crianças nas práticas sociais da leitura e da escrita, tendo em vista se constituir num "[...] processo complexo e multifacetado que envolve ações especificamente humanas". (MORTATTI, 2010, p. 329).

O ideário de alfabetizar letrando influenciou as políticas públicas de formação docente, com ênfase nas formações continuadas. $O$ 
Programa de Formação de Professores Alfabetizadores (PROFA) e os Parâmetros Curriculares Nacionais (PCN'S) em ação foram elaborados tendo como base as propostas construtivistas, proporcionando processos coletivos de reflexão. Sob essa perspectiva a formação continuada surgiu como "[...] concepção de formação no próprio local de trabalho [...]", pois promove a reflexão e aperfeiçoamento da prática pedagógica contribuindo para que sejam encaminhadas ações que atendam às necessidades das instituições de ensino em que o professor está inserido. (FREITAS, 2002, p. 149).

Compreende-se que por tratar da formação continuada em exercício, focaliza o processo formativo na área de atuação do professor, como acontece na formação continuada oferecida para os professores alfabetizadores que tem buscado nortear o trabalho pedagógico no intuito de alfabetizar todas as crianças até o 3 음 ano do Ensino Fundamental.

No atual PNE (Lei n. 13.005/14), por exemplo, a meta 5 trata sobre a alfabetização e aponta a necessidade de:

\section{[...] promover e estimular a formação inicial e continuada de professores (as) para a alfabetização de crianças, com o conhecimento de novas tecnologias educacionais e práticas pedagógicas inovadoras, estimulando a articulação entre programas de pós-graduação stricto sensu e ações de formação continuada de professores (as) para a alfabetização. (BRASIL, 2014, p. 3).}

Em conformidade com o que determina o PNE, o município de Campo Grande assegurou na meta 5 (cinco) do Plano Municipal de Educação (PME/2015-2025), a necessidade de "[...] estruturar os processos pedagógicos de alfabetização, [...], por meio de implementação da formação continuada de professores (as) alfabetizadores (as), [...] instrumentalizando-os (as) para organização do trabalho pedagógico". (CAMPO GRANDE, 2015, p. 35).
Nesse documento, portanto, as formações continuadas são concebidas como meio de organizar o trabalho pedagógico do professor alfabetizador, possibilitando a estruturação da prática docente com o intuito de melhorar a qualidade do processo de ensino-aprendizagem nas áreas de Língua Portuguesa e Matemática. Tal entendimento tem norteado os programas oficiais de formação elaborados e implementados pelo MEC em parceria com Estados e Municípios, tais como, o Pró-Letramento e o PNAIC em âmbito nacional e Aposta no Professor na esfera municipal, que foi ofertado aos professores alfabetizadores da REME em Campo Grande/MS.

A análise do material desses programas de formação evidenciou a abordagem de temáticas relacionadas ao alfabetizar-letrando, à avaliação, ao planejamento, à organização do trabalho pedagógico, ao processo de aquisição da língua escrita, entre outros, com o intuito de nortear a prática pedagógica do professor, tendo como pressuposto metodológico a concepção do aprender a aprender, aprender fazendo.

Nessa perspectiva, à concepção de docência está relacionada à mediação ${ }^{2}$. Logo, o professor alfabetizador é visto como o mediador do processor educativo devido à complexidade que envolve a aprendizagem da leitura e da escrita. Assim, "Uma formação pautada no pressuposto do professor reflexivo sem maiores questionamentos pode reforçar [...] à existência da dicotomia entre teoria e prática", reduzindo o papel do professor a mero executor e organizador de tarefas. Logo, defende-se que os programas formativos devem centrar as discussões nesses dois aspectos - teoria e prática - possibilitando aos professores a constituição de saberes sólidos com reflexões que ultrapassem a transposição didática. (VIEGAS; SIMIONATO; BRIDI, 2009, p. 74).

Contudo, as análises evidenciaram um forte apelo as discussões da prática pedagógica ${ }^{3}$,

\footnotetext{
2 Segundo Oliveira (1993) “Mediação, em termos genéricos, é o processo de intervenção de um elemento intermediário numa relação; a relação deixa, então, de ser direta e passa a ser mediada por esse elemento". (OLIVEIRA, 1993, p.26 - grifos da autora).

${ }^{3}$ Para Caldeira e Zaidan (2010), "[...] a prática pedagógica é entendida como uma prática social complexa, acontece em diferentes espaços/tempos da escola, no cotidiano de professores e alunos nela envolvidos e, de modo especial, na sala de aula, mediada pela interação professor-aluno-conhecimento" (CALDEIRA; ZAIDAN, 2010, p. 2).
} 
impulsionando professores alfabetizadores a se tornarem reprodutores de métodos oficiais de ensino, conforme podemos observar nos trechos retirados dos cadernos de formação do PróLetramento e PNAIC, respectivamente: “[...] é particularmente recomendável que [...] a sistematização em sala de aula se oriente pelo critério da progressão, indo do mais simples para o mais complexo [...]". (BRASIL, 2008, p. 35). "Para a compreensão do Sistema de Escrita Alfabética [...] podem ser propostas atividades que desafiem os discentes [...], como, por exemplo, a promoção diária de jogos e brincadeiras [...]". (BRASIL, 2012, p. 20). Tais orientações restringem a atuação do professor alfabetizador pois ditam como e quais conteúdos devem ser trabalhados na sala de aula, influenciando a concepção de docência desse profissional à medida que vai perdendo autonomia no encaminhamento do processo educativo.

Longe de garantir a qualidade tão almejada da educação, essas formações direcionaram o olhar da sociedade para o trabalho dos professores que passaram a ser culpabilizados pelos baixos índices de aprendizagem e vistos como despreparados. Precisavam, portanto, serem submetidos às formações que centrassem as discussões na reprodução de métodos com o intuito de alavancar os índices educacionais, ignorando-se, assim, outras nuances que permeiam o processo de ensino-aprendizagem na escola, dentre as quais, a falta de investimentos em educação.

Esse propósito se fez presente no argumento de Pedro Demo, elaborador e assessor do programa Aposta no Professor, oferecido pela SEMED aos professores da REME, ao ressaltar que "[...] o curso é para o professor, mas a prova dos nove é a aprendizagem do aluno" (DEMO, apud PASSOS, 2016, p. 75). A prova dos nove, portanto, é verificada por meio da aplicação das avaliações em larga escala, cujos resultados são compreendidos como determinantes da aprendizagem, ou não, dos conteúdos por parte dos alunos.

Constatamos, portanto, a distorção que envolve os programas de formação continuada tanto na esfera federal quanto municipal, tendo em vista que o foco está nos resultados obtidos por meio da formação e não no processo formativo em si, fato que interfere na concepção de docência do professor alfabetizador.

\section{CONCEPÇÃO DE DOCÊNCIA: O QUE PENSAM OS PROFESSORES ALFABETIZADORES}

A concepção de docência do professor alfabetizador vem sendo constituída por meio das vivências pessoais enquanto aluno e professor, dentro e fora da escola, pelos saberes profissionais provenientes da formação inicial e continuada, bem como dos saberes da experiência frente à sua atuação na sala de aula.

Assim sendo, os saberes e experiências vivenciados ao longo de todo o seu processo formativo se constituem "[...] fontes de suas conviç̧ões, crenças ou representações, frequentemente defendidas como certezas, em relação com diversos aspectos do ofício de professor: papel do professor, aprendizagem, características dos alunos, estratégias pedagógicas, gestão da classe etc." (TARDIF; RAYMOND, 2000, p. 220).

Logo, a concepção de docência está entrelaçada por saberes e experiências vivenciadas desde a mais tenra idade, configurando a práxis e determinando o modo como se compreende a alfabetização e como se encaminha o processo educativo nas turmas de 1 , 2 ㅇ e 3 음 anos do Ensino Fundamental.

Assim, a pesquisa foi realizada em 5 (cinco) escolas municipais, localizadas nas diferentes regiões urbanas de Campo Grande/MS. Em cada uma dessas instituições entrevistamos 1 (uma) professora alfabetizadora, identificadas pela sigla P1, P2, P3, P4 e P5, respectivamente.

Traçando um perfil inicial das participantes da pesquisa identificamos que todas eram concursadas, pedagogas e com vasta experiência nas turmas de 1ㅇ, 2ㅇ e 3 ㅇ anos do Ensino Fundamental, entre 5 (cinco) e 25 (vinte e cinco) anos de atuação nas salas de alfabetização, evidenciando que "[...] Com o tempo de efetivo trabalho profissional, determinados saberes são aprendidos, apropriados e mobilizados pelos professores para atender as necessidades do processo de alfabetização", constituindo sua concepção de docência alfabetizadora. (HOÇA, 2015, s/p).

Nas entrevistas foram coletadas informações relacionadas ao ingresso e permanência nas salas de alfabetização, formação inicial e continuada, processo de ensinoaprendizagem e políticas públicas de formação 
realizadas no período de 2005 a 2016 em Campo Grande/MS, com o intuito de entrelaçar a concepção de docência do professor alfabetizador, à concepção de docência da SEMED, implícita nas ações e encaminhamentos do processo de ensinoaprendizagem da rede municipal, bem como das formações continuadas em serviço ofertadas por essa instituição.

Quanto à lotação em salas de alfabetização 4 (quatro) docentes (P1, P3, P4 e P5) relataram que só descobriram que seriam regentes nas turmas do 10 ao 3 o anos do Ensino Fundamental, ao se apresentarem à gestão escolar e serem comunicadas que eram as únicas turmas disponíveis na época.

P2, que já era professora da REME, fez o seguinte relato: "[...] quando eu cheguei a diretora perguntou qual a minha experiência, [...]. Eu falei que era 5o ano... ela falou, [...], você ainda não sabe, mas você é alfabetizadora, então eu vou te dar um 2 ㅇ ano (sic) [...]". (P2, 2018).

Apesar de P2 expor para a diretora sua experiência com as turmas de 50 ano, a gestora lhe designou uma turma de 20 ano, "[...] não levando em consideração sua vontade, motivação, conhecimento e aptidão para trabalhar com esse nível de ensino". (VALLE, 2014, p. 61). Logo, a docência alfabetizadora na REME adquire um status de casualidade à medida que a instituição não oferece opção de escolha ao profissional que toma posse no concurso público.

A inexistência de uma política de alfabetização na REME resultou, consequentemente, na falta de especificidade do concurso público para a etapa da alfabetização, bem como na ausência de ações que garantissem e viabilizassem aos professores a permanência na função de alfabetizadores. Isso acabou acarretando instabilidade do professor na função de alfabetizador, rotatividade docente, realização de formações centradas na prática pedagógica e a responsabilização de docentes alfabetizadores pelos resultados insatisfatórios. Em suma, a falta de uma política de alfabetização contribuiu para uma desvalorização do papel do professor alfabetizador em Campo Grande/MS.

Nessa perspectiva, constatamos que 0 ofício da docência alfabetizadora na REME adquire um status de casualidade à medida que a instituição não oferece opção de escolha ao profissional que toma posse no concurso público para o Ensino Fundamental I. Desta forma, aqueles que assumem as turmas de 1 , 2 으 e 3 o anos são considerados alfabetizadores, mesmo diante do fato de muitos não se identificarem, não se sentirem preparados e/ou não terem aptidão para trabalhar com essa etapa escolar.

Questionamos se as professoras se sentiam preparadas quando assumiram as salas de alfabetização. As professoras P1 e P3, que eram recém formadas, relataram que não se sentiam preparadas, pois não tinham experiência. P2 relatou que apesar de ter experiência nas turmas de 5o ano, teve medo por achar a alfabetização uma etapa difícil e complicada. Assim, o que se apreende das falas é que "[...] para os professores iniciantes, muito do que se aprende sobre a profissão acontece na prática, ou seja, no próprio trabalho, por isso consideram que estavam mal preparados, principalmente, para enfrentar as situações difíceis". (SLAVEZ, 2012, p. 52).

Esse sentimento de despreparo é natural em professores que estão iniciando a carreira docente tendo em vista que, em alguns casos, assumir uma sala de aula, após aprovação em concurso público, se constitui no primeiro grande desafio desses profissionais com relação ao ofício da docência, especialmente pelo contato direto com as experiências do cotidiano escolar.

Além disso, a forma como os professores ingressam nas salas de alfabetização é outro fator que contribui para deixá-los apreensivos e inseguros, tendo em vista que só sabem as turmas com as quais irão trabalhar no momento em que chegam à instituição de ensino e se apresentam aos diretores escolares. Já para as professoras P4 e $P 5$, que vinham trabalhando com as turmas de alfabetização como professoras convocadas, a efetivação da regência foi encarada como continuidade do trabalho já desempenhado.

Nessa perspectiva, inferimos que as experiências vivenciadas pelas professoras frente às salas de alfabetização, aliadas às formações continuadas oferecidas pela SEMED, contribuíram para o delineamento da concepção de docência do professor alfabetizador, à medida que "[...] a construção da identidade profissional está intrinsecamente relacionada às vivências dos professores em seu espaço de atuação [...]". (BOLZAN; MILLANI, 2013, p. 189). 
As professoras entrevistadas também responderam se já haviam pensado em deixar a alfabetização para atuarem em turmas de outros anos escolares. A professora P3 respondeu: "No começo até que eu pensei [...] porque [...] o resultado da alfabetização não é de imediato, [..]". (P3, 2018). Essa resposta evidencia sua concepção de docência alfabetizadora, afirmando que a alfabetização ocorre em processo gradual, num ciclo do 1음 ao 3 o anos do Ensino Fundamental. Já a professora P5 ressaltou que o incentivo e apoio da equipe pedagógica foram fundamentais para que ela assumisse e permanecesse como alfabetizadora na instituição de ensino. As professoras P2 e P4 afirmaram que a atuação nas salas alfabetizadoras impulsionou a permanência nessa etapa escolar, confirmando o que Tardif e Raymond (2000) já sinalizaram sobre o exercício da docência, ou seja, que "[...] o trabalho modifica o trabalhador e sua identidade, [...] na medida em que trabalhar remete a aprender a trabalhar, ou seja, a dominar progressivamente os saberes necessários à realização do trabalho [...]". O exercício da docência, portanto, permite que os professores se adaptem a essa etapa escolar, reconhecendo-se como alfabetizadores e permanecendo nessa função no interior da instituição de ensino. (TARDIF; RAYMOND, 2000, p. 210).

A professora $\mathrm{P} 1$ evidenciou a afinidade como motivo de sua permanência na alfabetização, mas ressaltou os percalços que enfrenta no exercício da docência: desmotivação, cobranças, excesso de trabalho, resultados insatisfatórios, etc. A origem desses sentimentos pode estar relacionada ao modo como a SEMED encaminha o processo alfabetizador, ou seja, quando permite número excessivo de alunos em salas de alfabetização deixando à parte as especificidades vivenciadas no contexto educativo; quando propõe a execução de projetos provenientes das parcerias firmadas com outros órgãos do estado sem diálogo com os professores, além das atividades inerentes à profissão, tais como: elaboração, aplicação, correção de provas, preenchimento de planilhas e diários de classe, entre outras. Tais encaminhamentos evidenciam que a concepção de docência da SEMED está diretamente relacionada à percepção do professor como um executor de tarefas.
Questionadas sobre o que caracteriza um professor alfabetizador, as professoras P1 e P5 ressaltaram que é o profissional que está sempre se questionando, estudando e pesquisando. A professora P4 evidenciou a afetividade como uma importante característica que precisa compor o perfil do docente alfabetizador. Já P3 se reportou às questões metodológicas para caracterizar o professor como alfabetizador. Todos esses atributos refletem suas particularidades, seus modos de ser e agir, demonstrando que "[...] os papéis profissionais por eles desempenhados remetem a normas que eles devem adotar em relação a essa ocupação", sendo assim, são características que foram sendo internalizadas e vivenciadas no decorrer da constituição da concepção de docência alfabetizadora. (TARDIF; RAYMOND, 2000, p. 224).

A professora $\mathrm{P} 2$ ressaltou que, além da metodologia, "[...] ele tem que entender dos níveis silábicos [...]". (P2, 2018). A fala dessa professora evidencia a concepção de docência atrelada à ideia de que para se ensinar é necessário ter conhecimentos específicos sobre o que é ensinado. O que nos leva a refletir sobre as formações continuadas ofertadas aos professores alfabetizadores centradas nas práticas do ensino, não desvelando para os docentes a teoria por trás da prática que permeia o processo de formação.

Dando continuidade às entrevistas questionamos as professoras sobre o processo de alfabetização a partir do Ensino Fundamental de 9 (nove) anos. As professoras P1, P2, P3 e P4 esboçaram preocupações e angústias relacionadas à maturidade das crianças, expondo como principal dificuldade $o$ fato delas não conseguirem acompanhar as exigências e os conteúdos previstos para essa etapa escolar, evidenciando a concepção de docência que compreende a alfabetização em idades específicas. Assim, crianças de 6 anos "[...] não estariam "prontas" para estar no 10 ano". (PANSINI; MARIN, 2011, p. 99). Nesse contexto, a alfabetização enquanto processo de aprendizagem é sobreposta pela ideia de que há um momento certo e/ou uma idade certa para se alfabetizar.

O que identificamos como problema, mediante as respostas das professoras, não é a idade das crianças, mas a percepção que se têm delas e ressaltamos que possa estar relacionada à cobrança que as professoras alfabetizadoras 
recebem por resultados, levando-as a centrar ações nos conteúdos, ficando a ludicidade e o brincar em 2 ㅇpono.

A professora P5 esboçou uma concepção de docência diferenciada das demais ressaltando a formação (inicial e continuada) como aliada no desenvolvimento do trabalho docente no Ensino Fundamental de 9 (nove) anos, afirmando que,

$$
\begin{aligned}
& \text { [...] quanto mais cedo você } \\
& \text { vai trabalhando com a } \\
& \text { criança, não de uma forma } \\
& \text { impositiva, [...] ela se } \\
& \text { apropria mais rápido, né. Só } \\
& \text { que não pode ser algo } \\
& \text { forçado, [...]. Tem que ser } \\
& {[\ldots . .] \text { um processo }} \\
& \text { construtivo, tá. [...], mas o } \\
& \text { professor tem que saber } \\
& \text { trabalhar isso e pra isso } \\
& \text { precisa de formação. A } \\
& \text { formação que tem que } \\
& \text { iniciar lá no banco da } \\
& \text { Universidade, né. E reforçar } \\
& \text { no sistema, ou seja, ser } \\
& \text { reforçado pelo Governo } \\
& \text { Federal, [...] Estadual, [...] } \\
& \text { Municipal, [...]. (P5, 2018). }
\end{aligned}
$$

Para a professora P5 a concepção de docência na alfabetização evidencia a importância da formação inicial e continuada na capacitação dos professores para atuarem no Ensino Fundamental de 9 (nove) anos, já que "[...] com a entrada da criança aos 6 anos de idade na escola obrigatória, os professores precisam estar preparados para se relacionar com elas [...]". (PANSINI; MARIN, 2011, p. 92).

Assim, concepções relacionadas ao fato das professoras considerarem as crianças imaturas para a alfabetização (centralizando o processo de ensino-aprendizagem no aluno), só serão resolvidas com formações sustentadas por discussões que aliem a teoria, a prática e as especificidades vivenciadas pelos professores na sala de aula, possibilitando aquisição de novos saberes e um olhar crítico sobre o processo de ensinoaprendizagem das crianças com 6 (seis) anos de idade.

Nesse sentido, portanto, o processo formativo assume um papel imprescindível na reestruturação da concepção de docência do professor alfabetizador, no intuito de prepará-lo para atuar com os sujeitos e as peculiaridades que compõem o ciclo de alfabetização no Ensino Fundamental de 9 (nove) anos.

Assim, o curso de Pedagogia, responsável pela formação inicial, precisa propiciar estudos aprofundados sobre a temática da alfabetização em sua estrutura curricular. Já a formação continuada, efetivada por meio dos programas oficiais, precisam com urgência reconfigurar seu caráter informativo, pois não tem oferecido "[...] subsídios teóricos para trabalhar novas concepções de criança, de infância, de alfabetização e letramento, de ludicidade, [...]", distanciando-se da vivência e das dificuldades enfrentadas pelos professores no decorrer do processo de ensinoaprendizagem focalizando em ações para alavancar índices educacionais (FERRARESI, 2015, p. 93). Nessa perspectiva, constatamos que as políticas de formação continuada são subsidiadas pela concepção de docência que vê o professor como um mediador do ensino a quem cabe elaborar e executar tarefas.

Questionadas se as políticas e ações implementadas pela SEMED têm colaborado para a alfabetização das crianças até os 8 (oito) anos de idade, P2, P4 e P5 ressaltaram que a formação do PNAIC contribuiu positivamente para a concretização desse objetivo, contudo evidenciaram que esse programa foi perdendo o significado a partir de 2015, quando passou a abranger outras disciplinas curriculares, momento em que os encontros regulares com os orientadores de estudo, em polos, no horário de trabalho, foram substituídos por encontros e palestras no período noturno, na SEMED.

Já P1 e P3 expuseram que as políticas e ações implementadas pela SEMED não tem contribuído para efetivação do processo de alfabetização, já que as salas estão superlotadas e, com relação às formações, P3 ressaltou que "[...] não é [...] ir lá e fazer leitura de textos e ver atividades que vem se repetindo. [...], é atender a necessidade da escola. [...]". (P3, 2018).

$\mathrm{O}$ posicionamento de P3 evidencia o distanciamento das discussões propostas nas formações à realidade vivenciada no chão da escola, que não suprem as necessidades reais da ação educativa, pois estão "[...] a serviço dos programas oficiais de ensino [...]", propondo discussões de práticas e modelos que se reflitam 
em bons resultados nas avaliações. Logo, a concepção de docência restringe-se à reprodução de métodos, ficando cada vez mais distante do processo educativo experienciado na sala de aula. (MORTATTI, 2008, p. 474).

Afirmamos, portanto, que as formações precisam articular os estudos e reflexões ao contexto de atuação docente, buscando atender as especificidades vivenciadas no dia-a-dia da sala de aula, valorizando saberes e proporcionando o desenvolvimento profissional, ressignificando a concepção de docência do professor alfabetizador.

\section{CONSIDERAÇÕES FINAIS}

As pesquisas realizadas no decorrer desse trabalho evidenciaram a inexistência de uma política pública de alfabetização em Campo Grande/MS refletida na lotação de professores pela gestão escolar, ignorando-se à afinidade e aptidão desse profissional para atuar nessa etapa educativa, a rotatividade docente e a necessidade de formações continuadas em serviço.

As análises dos programas Pró-Letramento, PNAIC e Aposta no Professor revelaram que a concepção de docência embutida nessas políticas públicas de formação vê o professor alfabetizador como mediador do ensino, a quem cabe elaborar e executar tarefas. Nessa perspectiva, centralizavam as discussões na prática docente difundindo métodos oficiais com o objetivo de alavancar índices de aprendizagens aferidos nas avaliações em larga escala. Tal prática formativa embute, portanto, uma política de responsabilização que direciona para o professor alfabetizador o encargo pelos baixos índices de aprendizagem aferidos e, consequentemente, pela baixa qualidade do ensino no país e no município de Campo Grande/MS.

A afetividade, a aptidão para trabalhar na etapa da alfabetização, além da exigência de estar sempre estudando, pesquisando e dominar saberes sistematizados que permeiam o campo da alfabetização, são aspectos que remetem à concepção de docência das professoras participantes da pesquisa, pois retrata um perfil traçado no decorrer dos seus processos formativos.

Constatamos que as professoras compreendem a alfabetização como um processo de aprendizagem que se desenvolve num ciclo de 3 (três) anos, do 1ㅇ ao 3o anos do Ensino Fundamental, permitindo aos alunos avançarem, gradualmente, em suas aprendizagens. Contudo, diante das dificuldades enfrentadas no trabalho docente a partir do Ensino Fundamental de 9 (nove) anos, evidenciamos outra concepção de docência que compreende a alfabetização articulada com a maturidade, sobrepondo-se à concepção de alfabetização enquanto processo de aprendizagem.

Essa constatação alerta para a necessidade de repensar as formações colocando em pauta as especificidades vivenciadas no contexto educativo aliadas à teoria e à prática. Assim, concepções que relacionam a aprendizagem com maturidade, poderão ser desconstruídas possibilitando uma reflexão crítica sobre os equívocos que permeiam o processo de alfabetização, adquirindo novos saberes e ressignificando a concepção de docência do professor alfabetizador da REME em Campo Grande/MS.

\section{REFERÊNCIAS}

BOLZAN, Doris Pires Vargas. MILLANI, Silvana Martins de Freitas. Aprendizagem da docência alfabetizadora: desafios à formação. Revista Contrapontos, Itajaí, v . 13, n. 3, p. 186-194, set./dez. 2013. Disponível em: https://siaiap32.univali.br//seer/index.php/rc/artic le/view/5107. Acesso em: 21 abr. 2017.

DOI:10.14210/contrapontos.v13n3.p186-194

BRASIL. Congresso Nacional. Lei № 13.005 de 25 de junho de 2014. Aprova o Plano Nacional de Educação - PNE e dá outras providências. Diário Oficial da União. Seção 1. Edição Extra. Brasília/DF, 26 de junho de 2014. p. 1-7. Disponível em: http://portal.imprensanacional.gov.br/acervodou/2014/jun/26. Acesso em: 21 abr. 2017.

BRASIL. Ministério da Educação. Pró-Letramento: Programa de Formação Continuada de Professores dos Anos/Séries Iniciais do Ensino Fundamental: alfabetização e linguagem. Ed. rev. e ampl. incluindo SAEB/Prova Brasil matriz de referência/Secretaria de Educação Básica. Brasília: Ministério da Educação, Secretaria de Educação Básica, 2008.

BRASIL. Secretaria de Educação Básica. Diretoria de Apoio à Gestão Educacional. Pacto Nacional pela Alfabetização na Idade Certa: Formação do 
Professor Alfabetizador: caderno de apresentação. Ministério da Educação, Secretaria de Educação Básica, Diretoria de Apoio à Gestão Educacional. Brasília: MEC, SEB, 2012.

CALDEIRA, A. M. S; ZAIDAN, S. Prática pedagógica. $2010 . \quad$ Disponível em: http://www.gestrado.org/pdf/328.pdf Acesso em: 04/03/2019.

CAMPO GRANDE. Lei no 5.565 de 23 de junho de 2015. Aprova o Plano Municipal de Educação do Município de Campo Grande - MS e dá outras providências. PME 2015-2025. Diário Oficial de Campo Grande-MS, Suplemento I, Campo Grande/MS, 24 de junho de 2015. 46p. Disponível em:

http://www.capital.ms.gov.br/cme/downloads/pla no-municipal-de-educacao-campo-grandems-pme2015-2025/. Acesso em: 21 abr. 2017.

DINIZ-PEREIRA, J. E. A construção do campo de pesquisa sobre formação de professores. Revista da FAEEBA: Educação e Contemporaneidade. Salvador, v. 22. n. 40. p. 145-154. , jul./dez, 2013. Disponível

em: https://www.revistas.uneb.br/index.php/faeeba/ar ticle/view/7445. Acesso em: 21 abr. 2017.

DINIZ-PEREIRA, J. E. As licenciaturas e as novas políticas educacionais para a formação docente. Educação \& Sociedade, Campinas, v. 20, n. 68, p. 109-125, dez. 1999. Disponível em: https://www.scielo.br/scielo.php?script=sci arttext \&pid=S0101-73301999000300006\&lng=pt\&t|ng=pt. Acesso em: 21 abr. 2017.

DOI: $10.1590 /$ S0101-73301999000300006

DINIZ-PEREIRA, J. E. Da racionalidade técnica à racionalidade crítica: formação docente $\mathrm{e}$ transformação social. Perspectivas em diálogo: Revista de Educação e Sociedade, Naviraí, v. 01, n.01, p. 34-42, jan./jun., 2014.

DINIZ-PEREIRA, J. E. Formação de professores, trabalho docente e suas repercussões na escola e na sala de aula. Educação \& Linguagem., v. 10, n. 15, p. 82-98, jan./jun. 2007. Disponível em: http://www.bibliotekevirtual.org/index.php/201302-07-03-02-35/2013-02-07-03-03-11/2014-07-19- 06-15-59/472-el/v10n15/3715-formacao-deprofessores-trabalho-docente-e-suas-repercussoesna-escola-e-na-sala-de-aula.html. Acesso em: 21 abr. 2017. DOI:10.15603/2176-1043/el.v10n15p82$\underline{98}$

FERRARESI, P. D. Ensino fundamental de nove anos: uma ampliação de direitos? 2015. $213 f$. Dissertação (Mestrado em Educação) - Faculdade de Filosofia, Ciências e Letras de Ribeirão Preto. Universidade de São Paulo, Ribeirão Preto, 2015.

FREITAS, H. C. L. Formação de professores no Brasil: 10 anos de embate entre projetos de formação. Educ. Soc., Campinas, v. 23, n. 80, p. 136-167, set. $2002 . \quad$ Disponível em: https://www.scielo.br/scielo.php?script=sci arttext \&pid=S0101-73302002008000009\&lng=pt\&t|ng=pt. Acesso em: 21 abr. 2017. DOI: $10.1590 /$ S0101-73302002008000009

FRIGOTTO, Gaudêncio. CIAVATTA, Maria. Educação básica no Brasil na década de 1990: subordinação ativa e consentida à lógica do mercado. Educ. Soc. Campinas, v. 24, n. 82, p.93-130, abr. 2003. Disponível em: https://www.scielo.br/scielo.php?script=sci arttext \&pid=S0101-73302003000100005\&lng=pt\&t|ng=pt. Acesso em: 21 abr. 2017. DOI: $10.1590 / \mathrm{S} 0101-73302003000100005$

HOÇA, L. Desenvolvimento profissional do professor alfabetizador. In: REUNIÃO NACIONAL DA ANPED, 37., 2015, Florianópolis. Anais... Florianópolis: UFSC, 2015.

MINAYO, M. C. S. et al. Pesquisa Social: Teoria, método e criatividade. 29. ed. Petrópolis, RJ: Vozes, 2010.

MORTATTI, M. R. L. História dos métodos de alfabetização no Brasil. In: SEMINÁRIO ALFABETIZAÇÃO E LETRAMENTO EM DEBATE, 1., 2006, Brasília. Anais...Brasília: MEC/SEB, 2006. p. 114.

MORTATTI, M. R. L. Notas para uma história da formação do alfabetizador no Brasil. Revista Brasileira de Estudos Pedagógicos, Brasília, v. 89, n. 223, p. 467-476, set./dez. 2008. 
MORTATTI, M. R. L.. (Org.). Alfabetização no Brasil: uma história de sua história. Marília: Oficina Universitária, 2011. Disponível em: https://www.marilia.unesp.br/Home/Publicacoes/a Ifabetizacao.pdf. Acesso em: 8 nov. 2016.

MOROSINI, M. C. et al. Enciclopédia de Pedagogia Universitária: Glossário - INEP/RIES (Rede Sulbrasileira de Investigadores da Educação Superior). Brasília: INEP/MEC, 2006. V.2

OLIVEIRA, M. K. Aprendizado e Desenvolvimento: um processo sócio-histórico. São Paulo. Scipione, 1993

PANSINI, F.; MARIN, A. P. O ingresso de crianças de 6 anos no ensino fundamental: uma pesquisa em Rondônia. Educação e Pesquisa, São Paulo, v. 37, n. 1, p. 87-103, jan./abr. 2011. Disponível em: https://www.scielo.br/scielo.php?script=sci arttext \&pid=S1517-97022011000100006\&lng=pt\&t|ng=pt. Acesso em: 21 abr. 2017.

DOI: $10.1590 /$ S1517-97022011000100006

PASSOS, T. M. T. S. Análise da implementação do programa de formação continuada dos professores da rede municipal de ensino de Campo Grande/MS (2005-2012): investimento no desenvolvimento profissional docente? 2016. 137f. Dissertação. (Mestrado Profissional em Educação) Universidade Estadual de Mato Grosso do Sul, Unidade Universitária de Campo Grande - MS. Campo Grande/MS, 2016.

SLAVEZ, M. H. C. Percursos identitários de Professores alfabetizadores no município de Paranaíba - MS. 2012. 182f. Tese. (Doutorado em Educação) - Pontifícia Universidade Católica de São Paulo - PUC/SP. São Paulo/SP, 2012.
SOARES, M. A reinvenção da Alfabetização. Presença Pedagógica, v. 9, n. 52, p. 15-21, jul./ago, 2003.

TARDIF, M.; RAYMOND, D. Saberes, tempo e aprendizagem do trabalho no magistério. Educação \& Sociedade, Campinas, v. 21, n. 73, p. 209-244, dez. 2000.2 Disponível em: https://www.scielo.br/scielo.php?script=sci arttext \&pid=S0101-73302000000400013\&lng=pt\&tIng=pt. Acesso em: 21 abr. 2017. DOI: 10.1590/S010173302000000400013

TARDIF, M. Saberes docentes e formação profissional. Petrópolis, RJ: Vozes, 2002.

TRIVIÑOS, A. N. S. Introdução à pesquisa em ciências sociais: a pesquisa qualitativa em educação. São Paulo: Atlas, 1987.

VALLE, R. C. D. Professora Alfabetizadora: Saberes Docentes nos Anos Iniciais. 2014. 82 f. Dissertação (Mestrado em educação) - Pontifícia Universidade Católica do Rio Grande do Sul. Porto Alegre/RS, 2014.

VIEGAS, L. T.; SIMIONATO, M. F.; BRIDI, F. S. R Formação de professores: uma análise preliminar do programa nacional de formação continuada dos professores da educação básica. Reflexão e ação, Santa Cruz do Sul, v. 17, n. 2., p. 69-90, jul./dez., 2009.

VIEIRA, S. R. Docência, gestão e conhecimento: conceitos articuladores do novo perfil do pedagogo instituído pela resolução CNE/CP N. 01/2006. Revista HISTEDBR On-line, Campinas, n. 44., p. 131-155, dez. 2011. Disponível em: https://periodicos.sbu.unicamp.br/ojs/index.php/h istedbr/article/view/8639982. Acesso em: $21 \mathrm{abr}$. 2017. DOI: 10.20396/rho.v11i44.8639982 